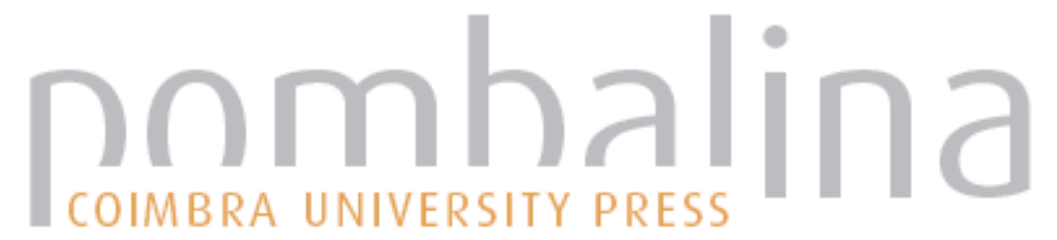

(8)

\section{Perceção de risco e confiança institucional entre crianças e jovens do Ensino Básico na RAM}

\author{
Autor(es): $\quad$ Gomes, Ricardo; Brites, Rafael \\ Publicado por: Imprensa da Universidade de Coimbra; RISCOS - Associação \\ URL \\ persistente: URI:http://hdl.handle.net/10316.2/34952 \\ DOI: $\quad$ DOI:http://dx.doi.org/10.14195/978-989-96253-3-4_152 \\ Accessed : $\quad$ 26-Apr-2023 11:48:14
}

A navegação consulta e descarregamento dos títulos inseridos nas Bibliotecas Digitais UC Digitalis, UC Pombalina e UC Impactum, pressupõem a aceitação plena e sem reservas dos Termos e Condições de Uso destas Bibliotecas Digitais, disponíveis em https://digitalis.uc.pt/pt-pt/termos.

Conforme exposto nos referidos Termos e Condições de Uso, o descarregamento de títulos de acesso restrito requer uma licença válida de autorização devendo o utilizador aceder ao(s) documento(s) a partir de um endereço de IP da instituição detentora da supramencionada licença.

Ao utilizador é apenas permitido o descarregamento para uso pessoal, pelo que o emprego do(s) título(s) descarregado(s) para outro fim, designadamente comercial, carece de autorização do respetivo autor ou editor da obra.

Na medida em que todas as obras da UC Digitalis se encontram protegidas pelo Código do Direito de Autor e Direitos Conexos e demais legislação aplicável, toda a cópia, parcial ou total, deste documento, nos casos em que é legalmente admitida, deverá conter ou fazer-se acompanhar por este aviso.

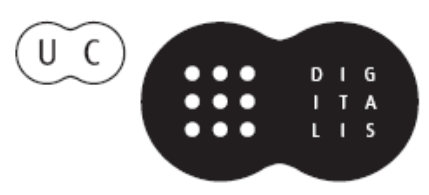



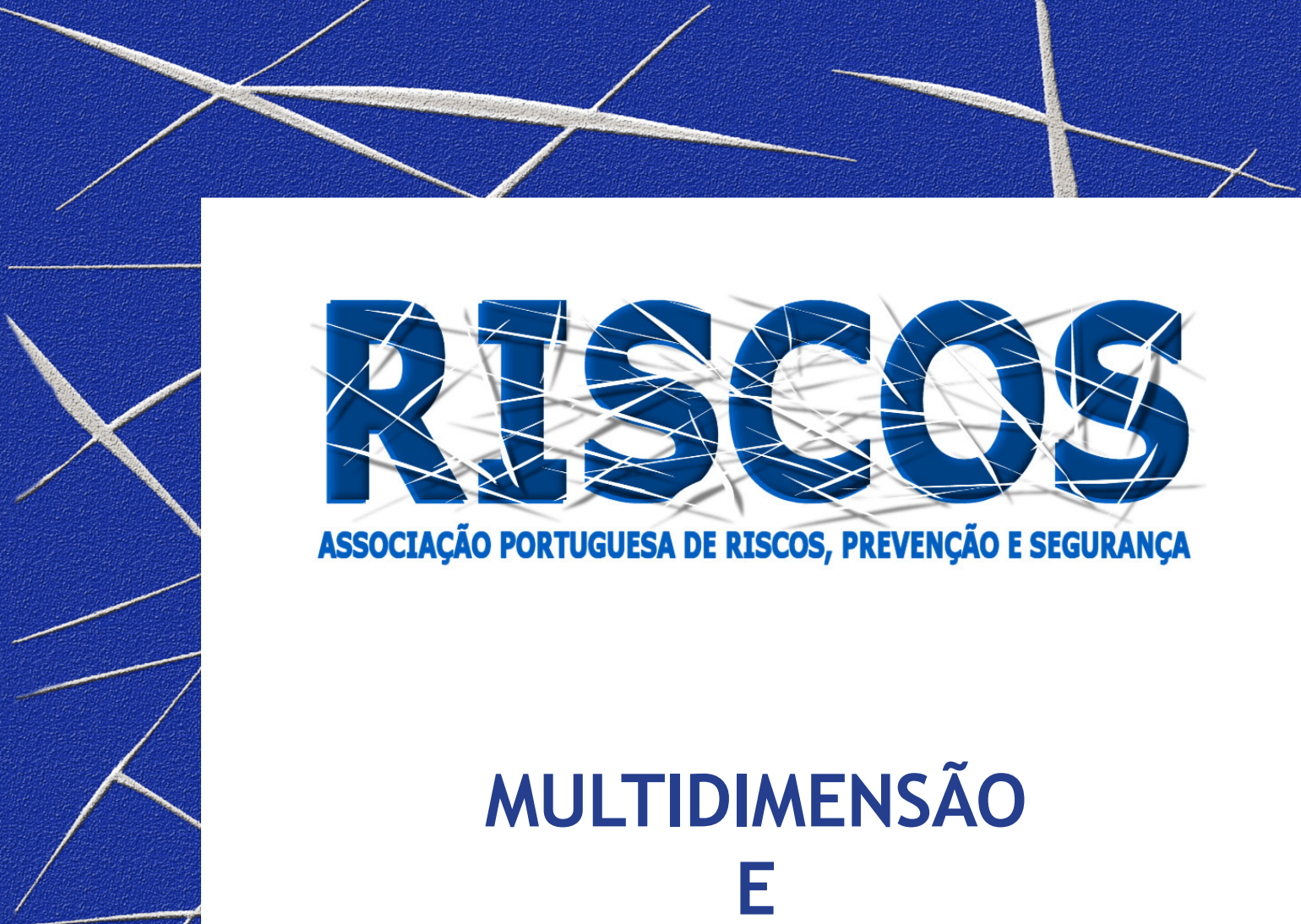

ASSOCIAÇÃO PORTUGUESA DE RISCOS, PREVENCCÃO E SEGURANÇA

MULTIDIMENSÃO

E
TERRITÓRIOS DE RISCO

III Congresso Internacional

I Simpósio Ibero-Americano

VIII Encontro Nacional de Riscos

Guimarães

2014 


\title{
PERCEÇÃO DE RISCO E CONFIANÇA INSTITUCIONAL ENTRE CRIANÇAS E JOVENS DO ENSINO BÁSICO NA RAM
}

\author{
Ricardo Gomes \\ Serviço Regional de Proteção Civil, IP-RAM \\ ricardo.gomes@procivmadeira.pt \\ Rafael Brites \\ Serviço Regional de Proteção Civil, IP-RAM \\ rafael.brites@procivmadeira.pt
}

\begin{abstract}
RESUMO
A perceção que os indivíduos têm dos riscos a que estão expostos, bem como a sua confiança nas instituições, influencia os seus comportamentos e, consequentemente, repercute-se na sua vulnerabilidade. Na Região Autónoma da Madeira (RAM), registaram-se nos últimos anos eventos naturais extremos com consequências gravosas, às quais as crianças e jovens são um grupo particularmente vulnerável.

Assim, torna-se relevante conhecer a perceção que as crianças da RAM têm sobre os riscos naturais a que estão expostas, sobre a sua segurança e confiança nas instituições que a promovem, bem como comportamentos de autoproteção adotados.

Nesse sentido, foi implementado um questionário sobre perceção de risco, confiança institucional e comportamentos de autoproteção, cujo público-alvo foram os alunos do $2^{\circ}$ e $3^{\circ}$ Ciclo do Ensino Básico da RAM. Com os resultados deste questionário traça-se um perfil de aluno e relacionam-se as respostas sobre perceção, confiança institucional e autoproteção com diferentes variáveis.
\end{abstract}

Palavras-chave: Perceção de risco; Confiança Institucional; Cultura de Segurança.

\section{Introdução}

A perceção que os indivíduos têm dos riscos a que estão expostos, bem como a sua confiança nas instituições e medidas de autoproteção, influencia os seus comportamentos e, consequentemente, repercute-se na sua vulnerabilidade. No mesmo sentido, a educação para estas questões e a realização de treinos e simulacros concorrem para aumentar a resiliência (Diego, 2012).

De facto, a análise das questões do Risco Natural não se devem circunscrever apenas aos processos e seus fatores desencadeantes ou tão pouco à previsão dos mesmos. Os riscos manifestam-se relativamente à população, cujas caraterísticas importa, portanto, conhecer (Brito Henriques e Queirós, 2009).

A análise da perceção dos riscos e da confiança nas instituições deve ter em consideração diferentes escalas de análise, mais local ou mais distal, bem como um conjunto de variáveis que as condicionam e onde se incluem questões relacionadas com informação e educação (Tavares et al, 2011).

Na Região Autónoma da Madeira (RAM), ocorrem ciclicamente manifestações de perigosidade às quais as crianças e jovens são um grupo particularmente vulnerável. Por outro lado, são um público preferencial da educação e sensibilização sobre riscos naturais e comportamentos de autoproteção. Nos últimos anos a colaboração de diferentes entidades, nomeadamente a Secretaria Regional de Educação e Recursos Humanos (SRE) e o Serviço Regional de Proteção Civil (SRPC) resultou num conjunto de medidas direcionadas às crianças e jovens, destacandose os projetos 'Educação para a Segurança e Prevenção de Riscos' que integrou no currículo escolar regional uma disciplina sobre segurança, riscos e autoproteção e o projeto 'Segurança em Casa, na Rua e na Escola' que visa a sensibilização para a segurança, gestão do risco e 
comportamentos de autoproteção, atuando nas escolas junto de alunos, professores, auxiliares e encarregados de educação.

Com este trabalho pretendeu-se avaliar a perceção que os alunos do $2^{\circ}$ e $3^{\circ}$ Ciclo do Ensino Básico da RAM têm sobre os riscos naturais a que estão expostos, sobre a sua segurança e confiança nas instituições que a promovem, bem como comportamentos de autoproteção a adotados. Com a análise da informação recolhida pretende-se facilitar a reflexão sobre as medidas de educação e sensibilização mais adequadas para aumentar a resiliência das crianças e jovens e estabelecer um ponto de referência que permita, posteriormente, avaliar o impacto das medidas implementadas, nomeadamente pelo SRPC e pela SRE.

\section{Método}

Para este estudo foi concebido e implementado um questionário, aplicado a alunos do $2^{\circ}$ e $3^{\circ}$ Ciclo do Ensino Básico da RAM. Este universo é composto por cerca de 15 mil alunos tendo a amostra sido constituída por 10 mil inquiridos, estratificados por concelho de residência e por ciclo de ensino. Os questionários foram previamente testados com a colaboração de três escolas distintas, de forma a apurar a clareza das questões colocadas e ajustar tempo necessário ao preenchimento. Os questionários foram aplicados em contexto de sala de aula na presença de um docente, utilizando um formulário on-line, durante o segundo e terceiro período escolar de 2014. Os resultados foram tratados estatisticamente utilizando o software IBM SPSS 19.

\section{Resultados}

A amostra é composta por $51 \%$ de rapazes e $49 \%$ de raparigas, $39 \%$ do $2^{\circ}$ Ciclo e $61 \%$ do $3^{\circ}$ Ciclo. Quanto à distribuição da amostra por concelho de residência, os concelhos mais representados são Funchal (29\%), Santa Cruz (19\%), Camara de Lobos (14\%), Machico (12\%), Ribeira Brava (10\%) e os restantes distribuídos pelos restantes 6 concelhos, uma distribuição muito semelhante à distribuição de alunos do $2^{\circ}$ e $3^{\circ}$ Ciclo por concelhos na RAM. A maioria dos inquiridos vive com o seu Encarregado de Educação (98\%). Mais de 75\% já participou num simulacro de evacuação de escola e $74 \%$ dos alunos acompanha regularmente os serviços noticiosos na comunicação social.

Questionados sobre o local em que se sentem mais seguros, $82 \%$ respondeu ser em sua casa. A maioria dos inquiridos (43\%) indica serem os pais/família os principais responsáveis pela sua segurança. Apenas, $16 \%$ considera serem eles próprios e $14 \%$ a escola. Os bombeiros foram referidos por $10 \%$ dos alunos e $5 \%$ referiu o SRPC.

Nas questões acerca de percepção de riscos é pertinente considerar um âmbito mais distal, neste caso o nível regional, e um âmbito mais proximal, neste caso um nível mais próximo do local de residência (Tavares et al, 2011). Questionados sobre o receio sentido relativamente a desastres naturais, no que se refere ao nível mais local, o concelho de residência, numa escala de 1 a 4, a média de respostas é de 2,97. Já no que se refere ao nível regional a média é de 2,85. Mais significativo, relativamente ao âmbito local a resposta mais representada (38\%) foi '4', o nível máximo da escala enquanto relativamente ao âmbito regional a resposta mais representada (39\%) foi ' 3 '.

A apreensão é portanto maior quanto aos desastres naturais que ocorrem no local onde vivem. Relativamente aos diferentes tipos de eventos, os que incutem maior receio são os tsunamis $(3,2)$, sismos $(3,1)$ seguidos por cheias/aluviões $(3,1)$ e incêndios florestais $(3,1)$. Também as erupções vulcânicas $(2,9)$ e movimentos de vertente $(2,9)$ obtiveram médias elevadas. Note-se, 
neste conjunto de eventos que incutem maior receio, o contraste entre aqueles que, sendo potencialmente mais destruidores são menos frequentes (e recebem maior atenção no currículo escolar do Ensino Básico), e aqueles que, tendo geralmente impacto mais localizado, têm no entanto maior recorrência na RAM, incluindo em anos recentes.

Já no que se refere à probabilidade de um desastre natural efetivamente ocorrer (nos 10 anos seguintes), a probabilidade de um destes fenómenos ocorrer é em média considerada superior quando se referem ao âmbito regional $(2,6)$ e inferior quando se referem ao local onde vivem $(2,3)$. 0 nível máximo da escala de probabilidade representa $20 \%$ das respostas quanto ao nível regional e apenas $13 \%$ referindo-se ao nível local. Ainda que os alunos temam mais um evento extremo no local onde vivem, consideram que a probabilidade de efetivamente ocorrer perto de casa é inferior.

Quer relativamente à região, quer relativamente ao local onde vivem, eventos como tsunamis, erupções e sismos são considerados pouco prováveis, enquanto eventos relacionados com precipitação intensa, incêndios florestais, agitação do mar, movimentos de vertente, cheias e fluxos aparecem como os que apresentam valores de probabilidade mais elevada.

Quanto à perceção dos eventos que habitualmente causam mais destruição, os mais referidos são os incêndios florestais, precipitação intensa, movimentos de vertente e, em menor grau, agitação do mar e cheias ou fluxos. Coincidentemente, nos últimos anos têm sido estes eventos a ter maior impacto e cobertura mediática na RAM.

Quando às fontes de informação sobre riscos naturais, as consideradas mais confiáveis são pais/ família $(3,6)$, bombeiros $(3,4)$, polícia e profissionais de saúde $(3,3)$. O SRPC e professores ocupam posição inferior $(3,1)$. Os órgãos de governo regional e local, a Internet e as redes sociais ocupam os últimos lugares.

Já quanto a quem confiam para os ajudar em caso de desastre, são novamente pais/família $(3,7)$, bombeiros $(3,5)$, polícia $(3,4)$ os mais bem cotados. O Serviço de Emergência Médica Regional $(3,3)$ e o SRPC $(3,1)$, os amigos $(3,1)$, docentes e profissionais de saúde $(3)$ ocupam posições inferiores. Os órgãos de governo local e regional são os que suscitam menor confiança.

Os alunos revelam sentir-se mais informados sobre os riscos a que estão expostos no seu âmbito local e menos informados quando se trata de riscos de âmbito regional. As respostas correspondentes ao nível mais elevado da escala correspondem a $14 \%$ no nível local e apenas $10 \%$ a nível regional. A maioria dos inquiridos sente-se informada sobre o que fazer em caso de desastre $(65 \%)$ ou muito informada $(15 \%)$. Valores semelhantes são referidos relativamente à informação sobre a quem pedir ajuda em caso de emergência. Refira-se que $87 \%$ indica conhecer o número de emergência.

Mais de metade dos alunos (53\%) referiu já ter sido afetado por fenómenos de precipitação intensa, sendo este o tipo de evento mais referido. As situações de temperatura elevada, cheias ou fluxos e incêndios florestais são referidos por $27 \%, 26 \%$ e $24 \%$ dos alunos, respetivamente. Além disso, $21 \%$ indica ter sido afetado, pessoalmente ou através de alguém da família próxima, por estragos ou destruição da habitação. Os danos ou destruição de automóvel são referidos por $19 \%$ e $16 \%$ referem situações com feridos e 15\% com óbitos na família próxima.

Relativamente às medidas de autoproteção adotadas pelas famílias um número elevado refere a existência de lista de contatos de família e amigos (80\%), lista de contatos de serviços de emergência (77\%), estojo de primeiros socorros (68\%), lanternas $(65)$ e rádio a pilhas $(49 \%)$. Naturalmente, a motivação para alguns destes cuidados pode não ser autoproteção relativamente 
a desastres naturais. Medidas mais específicas como combinar ponto de encontro familiar ou local de abrigo em caso de emergência (40\%) ou ter plano familiar de emergência (36\%) são bastante menos referidos.

\section{Conclusão}

A análise dos dados recolhidos evidenciou que existe nos alunos do $2^{\circ}$ e $3^{\circ}$ Ciclo do Ensino Básico uma perceção relativamente elevada da probabilidade de ocorrerem desastres naturais, que ainda assim varia com a escala de referência - é maior quando se referem ao âmbito regional e menor quando se referem ao âmbito local, mais perto do local onde vivem. Pelo contrário, em caso de ocorrência de desastre natural é maior o receio perante eventos que ocorram no âmbito mais local. Note-se que existe uma perceção que distingue entre eventos potencialmente muito destruidores mas pouco prováveis e eventos de maior recorrência mas de consequências mais limitadas.

Estas crianças consideram a família os primeiros responsáveis pela sua segurança e confiam sobretudo na família, bombeiros, polícia e profissionais de saúde para os informar sobre riscos naturais e para os proteger em caso de um evento extremo. Os órgãos de governo, internet e redes sociais suscitam bastante menos confiança.

Mais de metade dos inquiridos refere já ter sido afetado por situações de precipitação extrema. Um número significativo afirma ter estado exposto, diretamente ou através da família, a situações de danos ou perda de casa, ferimentos ou mesmo óbitos.

Existe uma significativa correlação entre a percepção de riscos e adopção de comportamentos de autoproteção e um conjunto de variáveis, como por exemplo a escala de análise, mais local ou mais distal, e a experiência prévia de eventos que tenham causado danos.

\section{Bibliografia}

Brito Henriques, E. e Queirós, M. (2009). Verdadeiros medos e falsas confianças: percepção de risco numa região de elevada perigosidade natural. In XI Colóquio Ibérico de Geografia 'La Geografia ante los Nuevos Retos Ambientales’ [CD-ROM, 15 pp]. Alcalá: Asociación de Geógrafos Españoles, Universidade de Alcalá e Associação Portuguesa de Geógrafos.

Diego, C. (2012). Desastres Naturais - Algumas considerações: Vulnerabilidade, Risco e Resiliência. Territorium, Revista da Associação Portuguesa de Riscos, Prevenção e Segurança, 19. Lousã, p. 19.

Tavares, A.; Mendes, J. e Basto, E. (2011) - Percepção dos riscos naturais e tecnológicos, confiança institucional e preparação para situações de emergência: O caso de Portugal continental. Revista Crítica de Ciências Sociais, 93 (2011). Coimbra, p. 187. 